\title{
Risk Factors Exposure during the First Life Year and Asthma Development among Albanian Children
}

Xhixha $\mathrm{F}^{1}$, Bakiri AH${ }^{2,3}$, Mingomataj $\mathrm{DC}^{3}$, Ibranji $\mathrm{A}^{4}$, Gurakuqi $\mathrm{A}^{5}$, Mingomataj EÇ , $^{\text {, }}$

${ }^{1}$ Multidisciplinary Tirana Policlinics No 3, Allergy Visiting Room, Tirana, Albania.

${ }^{2}$ Hygeia Hospital Tirana, Outpatients Service, Tirana, Albania.

${ }^{3}$ Albanian University, Faculty of Medical Sciences, Tirana, Albania.

4 “Our Lady of Good Counsel”" Outpatients' Service, Tirana, Albania.

${ }^{5}$ Medicine University of Tirana, Faculty of General Medicine, Tirana, Albania.

${ }^{6}$ Medicine University of Tirana, Faculty of Technical Medical Sciences, Tirana, Albania.

7 "Mother Theresa" School of Medicine, Department of Allergology \& Clinical Immunology, Tirana, Albania.

\begin{abstract}
Background: Different environmental factors are accused as risk factors (RF) in the development of allergic respiratory diseases. This study aimed to investigate the role of exposure to suspected RFs during the first life year in the development of childhood asthma among Albanian capital residents with a provincial or suburban origin.

Method: Parental reports about own asthmatic children (276, m 160, f 116, aged 1-14, mean age 5.6) were collected regarding conduction of cesarean delivery, breast feeding, exposure to high house humidity, pets, or to passive tobacco smoke, and presence of familiar atopy or atopic dermatitis during the first life year. These results were compared with a sample of non-allergic children (100, m 49, f 51, mean age 5.7), diagnosed with common upper respiratory infections.

Results: Conduction of cesarean section $(\mathrm{OR}=9.8, \mathrm{p}=0.0002)$, exposure to high humidity at home $(\mathrm{OR}=3.77, \mathrm{p}=$ $0.0001)$, or to passive tobacco smoke $(\mathrm{OR}=4.78, \mathrm{p}<0.0001)$, as well as presence of atopic dermatitis $(\mathrm{OR}=10.37, \mathrm{p}=$ $0.0001)$ was significantly associated with asthma development. Familiar atopy $(\mathrm{OR}=1.07)$ and exposure to pets $(\mathrm{OR}=1.66)$ resulted insignificant, whereas breast feeding resulted in protective factor $(\mathrm{OR}=0.48, \mathrm{p}=0.0134)$.

Conclusion: Cesarean section during birth, increased humidity level at home, atopy and passive tobacco smoke during the first life year could be RFs regarding the asthma development. The avoidance of mentioned factors at least during the mentioned period may reduce the development risk of this disease.
\end{abstract}

Keywords: Asthma; First Life Year; Risk Factors.

\section{*Corresponding Author:}

Ervin Ç. Mingomataj,

"Mother Theresa" School of Medicine, Department of Allergology \&

Clinical Immunology, Tirana, Albania.

E-mail: allergology@gmx.de

Received: September 18, 2015

Accepted: October 28, 2015

Published: November 02, 2015

Citation: Mingomataj EÇ, et al., (2015) Risk Factors Exposure during the First Life Year and Asthma Development among Albanian Children. Int J Clin Med Allergy. 03(4), 34-37. doi: http://dx.doi.org/10.19070/23322799-150008

Copyright: Mingomataj EÇ ${ }^{\circ}$ 2015. This is an open-access article distributed under the terms of the Creative Commons Attribution License, which permits unrestricted use, distribution and reproduction in any medium, provided the original author and source are credited.

\section{Introduction}

Asthma is one of the most common chronic respiratory disorders [1]. Many epidemiology studies have suggested an increasing trend of asthma especially in industrialized world, and that perinatal exposure to several risk factors and genetic predisposition have been associated with development of childhood asthma or other respiratory allergic diseases [1-4]. The identified risk factors of asthma and other respiratory allergic diseases include maternal smoking and environmental tobacco smoke, traffic-related pollution, antibiotics, home dampness, etc $[1,5-8]$. To further investigate the regional role of some of these environmental factors and their contribution to the first year of life in asthma development, we conducted a retrospective study in asthmatic subjects and the control group presented in a multidisciplinary clinic of Tirana (capital city of Albania).

\section{Methodology}

This study is focused on presence of familiar history for atopic diseases, development of atopic dermatitis and exposure to indoor risk factors during the first year of life on asthmatic children who were visited in our clinic during 2008-2010. The parents of each child respectively have provided written informed consent and completed self-administered questionnaires. They included questions about two optional answers yes or no regarding the mode of delivery (cesarean or natural), breast feeding, and exposure to high humidity in their dwellings, pets, or environmental passive smoking as well as presence of family atopic history or atopic dermatitis. The study consisted of 276 asthmatic children aged $1-14$ years (m 160, f 116, mean age 5.6 \pm 1.1 ), and a control group composed of 100 children ( $\mathrm{m} 49, \mathrm{f} 51$, mean age $5.7 \pm 1.4$ ), diag- 
nosed with acute common upper respiratory infections. Diagnosis of asthma was confirmed or excluded due to clinical examination, ISAAC questionnaire, presence or absence of obstruction during spirometry (including salbutamol reversibility test), and results of skin prick tests with Mediterranean aeroallergens. The same questions were addressed to parents of control group children after exclusion of respiratory allergic symptoms. The study group and the control group matched in regard to age and sex indexes. The comparative data were shown as odd ratio (OR) and confidence interval (CI), and chi2-test was used to evaluate the significance level. Statistical significance was settled for $\mathrm{p}<0.05$.

\section{Results}

Our study shows a significant association of bronchial asthma with cesarean delivery (46/276 vs. $2 / 100$, OR 9.8, CI 2.33-41.17, $\mathrm{p}=0.0002)$, high indoor humidity exposure (164/276 vs. 28/100, OR 3.77, CI 2.29-6.2, p = 0.0001), environmental tobacco smoke (105/276 vs. $12 / 100$, OR 4.78, CI 2.49-9.17, $\mathrm{p}=0.0001)$, as well as the presence of atopic dermatitis $(67 / 276$ vs. $3 / 100$, OR 10.37 , CI 3.18-33.78, $\mathrm{p}=0.0001)$. Breastfeeding on the other part resulted a protective factor $(194 / 276$ vs. $83 / 100$, OR 0.48, CI 0.27-0.87, $\mathrm{p}=0.0134)$. Both, family atopic history (38/276 vs. $13 / 100$, OR 1.07, CI 0.54-2.1, $\mathrm{p}=0.84)$ and pet exposure findings (43/276 vs. $10 / 100$, OR 1.66 , CI $0.8-3.45, p=0.17$ ) were statistically insignificant (see Table 1 and Figure 1).

\section{Discussion}

Asthma in itself is a disease depended on the interplay between genetic and environmental factors $[1,2,9]$. The main impact on both factors originates in intrauterine and early extra-uterine life that corresponds to increased plasticity period during novel immune maturation $[5,10,11]$. Specifically, it is estimated that period from mid-gestation until 2 years after birth is one of a particular concern relative to allergic diseases and asthma [5, 11]. Although most published studies are underpowered to study interactions between genetic polymorphisms and ambient exposures, the identified risk factors play an active role in biologic mechanisms of immunologic balance and responsiveness $[9,12]$. The emerging data onto our study demonstrated that especially developments of atopic dermatitis, and to a lesser extent, a familiar history for atopic diseases are non-environmental risk factors in the development of childhood asthma. Similarly to this, a recent German cohort evidenced an augmented asthma incidence of offspring up to adulthood in subjects with parental asthma and nasal allergy [13]. Developing dynamically through childhood, co-morbidity of atopic pathologies in children increases with age, reaching a higher frequency and persistence among subjects with parental atopy [4]. These findings indicate that allergy-related diseases should be neither seen nor studied as isolated entities.

In a previous study, we have found that younger generations of atopic respiratory patients report a family history of allergic disease about half as frequently as older ones, indicating for the existence of environmental factors in the development of asthma and allergic rhinitis [14]. Several observations in the past decades have clearly shown a mark difference in the prevalence between urban and rural regions, indicating that protective effect of the rural region consists of early exposure to microbes or microbial products

Table 1. Perinatal risk factors, atopy, and development of asthma.

\begin{tabular}{|c|c|c|c|c|c|}
\hline Risk factors & Asthma $\mathbf{( \% )}, \mathbf{n}=\mathbf{2 7 6}$ & Control $\mathbf{( \% )}, \mathbf{n}=\mathbf{1 0 0}$ & $\mathbf{O R}$ & $\mathbf{( C I} \mathbf{9 5} \mathbf{0})$ & $\mathbf{P}$ \\
\hline Cesarean delivery & $46(17)$ & $2(2)$ & 9.80 & $(2.33-41.17)$ & 0.0002 \\
\hline Breastfeeding & $194(70)$ & $83(83)$ & 0.48 & $(0.27-0.87)$ & 0.0134 \\
\hline High home humidity & $164(59)$ & $28(28)$ & 3.77 & $(2.29-6.20)$ & 0.0001 \\
\hline Pets & $43(16)$ & $10(10)$ & 1.66 & $(0.80-3.45)$ & 0.17 \\
\hline Passive tobacco smoking & $105(38)$ & $12(12)$ & 4.78 & $(2.49-9.17)$ & 0.0001 \\
\hline Familiar atopic history & $38(14)$ & $13(13)$ & 1.07 & $(0.54-2.10)$ & 0.84 \\
\hline Atopic dermatitis & $67(24)$ & $3(3)$ & 10.37 & $(3.18-33.78)$ & 0.0001 \\
\hline
\end{tabular}

Figure 1. Frequency (\%) of exposure to risk factors in control and asthma group during first life year.

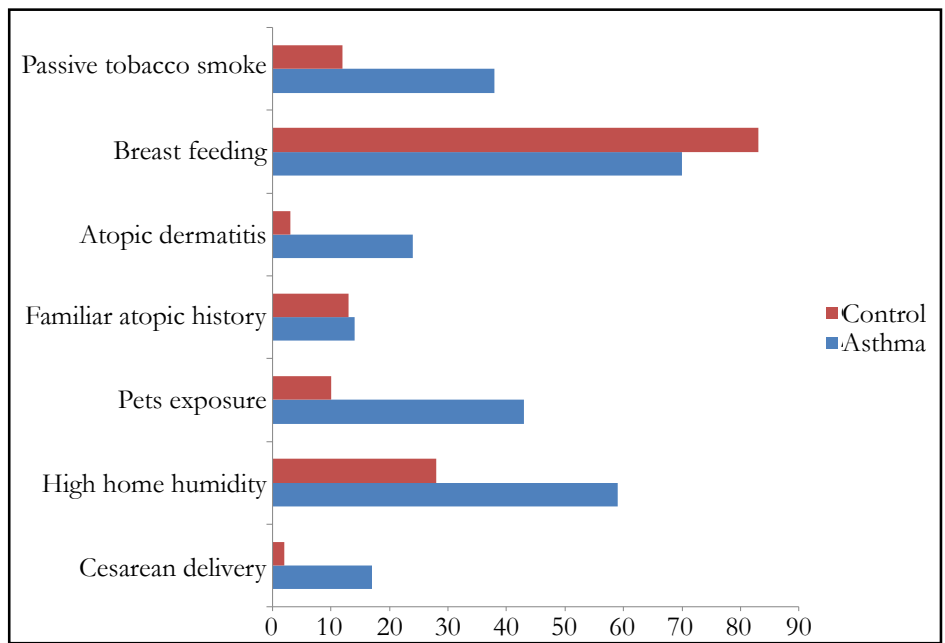

Breast feeding resulted as protective factor, pet exposure and familiar atopy were non-significant risk factors, whereas atopic dermatitis, cesarean delivery, high house humidity, and passive exposure to tobacco resulted as important risk factors. 
and modulating of the immune system so as to reduce the future risk of asthma and allergies [1]. It should be taken into account that the vast majority of our subjects originates from suburban regions that nowadays reside in the Albanian metropolis. Consequently, these subjects are generally exposed to a novel environment, even if asthma prevalence remains relatively low $[14,15]$.

In the present study, most of children are successors of the above-mentioned population, and during their first life year they are exposed to outdoors and mostly indoors allergens inside their dwellings [5]. Therefore, this might support the estimation, that many of these indoor and outdoor triggers have strong driving power over immature airway, toward "asthma battle" risk in later phases of their lives. With respect to indoor factors, our proper data evidenced a strong role in the pre-and perinatal exposure to environmental tobacco smoke. This agrees with little published data that emphasize the role of environmental tobacco smoke and other ambient air pollutants in the interaction with genetic polymorphism in asthma $[6,9,11]$. This exposure, with time leads to deficits in lung function, early onset of asthma, and respiratory-related school absenteeism among children [16-18]. In concert with other measures, avoiding tobacco smoke exposure to pregnancy, might prevent or delay the development of asthma [11, 13].

Home dampness during first life year is also reported on risk factors of the present survey. Independently to familiar history for atopy, associations between home dampness and respiratory diseases among children is proven through the protective influence of opening windows of the child's room at night and cleaning the child's room frequently $[6,19]$. Similarly to our study, early exposure to visible mould and/or dampness has been associated with an increased asthma risk [20]. These findings stress out the fact that modern hermetical and air conditioning environment leads to increased allergic burden indoors, and therefore, to high rates of persistent childhood asthma [21].

In contrast to environmental tobacco smoke and home dampness, our study suggested for a protective role in breastfeeding. It is postulated that breastfeeding provides immunological protection when the infant's immune system is immature and a modest protective effect against asthma in early childhood, while induction of epigenetic mechanism by colonizing bacteria results in a functional immune phenotype and no expression of disease [3, 22]. This protective effect has been evidenced in our study even though generally the breastfeeding in our country is very common, independently to the subsequent health outcome of the respiratory system $[11,22]$. Emerging data onto ISAAC multi-centric study also denied the consistent association with breastfeeding in the first life year and either a history or current symptoms of wheezing, rhino-conjunctivitis or eczema in 6-7 year old children [23]. Similarly to our study, breastfeeding for longer than four months among populations of certain industrialized countries have shown protective effects, especially among preschool age children with allergic heredity $[6,24,25]$. According to this evidence, the authors found out that introduction to preventive guidelines with regard to breastfeed (and other risk factors) during pre- and peri-natal age is associated with an important reduction of recurrent wheezing and asthma at 2 years of age [6].

Pet exposure (as a marker of infant exposure to distinct microbioma) revealed in present study as an insignificant risk factor of the development of childhood asthma, indicating that suburban origin and actual metropolitan life play a complex role on the genetic-environment relationship. Nevertheless, several studies have shown controversial or insignificant results in development of asthma and allergic sensitization [26-28]. Children originating from atopic parents living in households with indoor dogs at birth were less likely to develop frequent wheezes than those without indoor dogs' presentation, whereas this effect has been not proven in children exposed to cats $[26,29]$. Although perinatal exposure to pets might show a weak protective effect, sensitization to perennial household furry pets were associated with increased asthma risk [26, 28]. In summary, these findings indicated that pet ownership in early life did not appear to either increase or reduce the risk of asthma or allergic rhinitis symptoms in children [2730].

Similarly to pet exposure, delivery mode is considered a potential marker for infant exposure to distinct microbioma [28]. It is believed that premature and cesarean delivery can lead to inadequate intestinal colonization, resulting in the absence of adequate bacterial-epithelial "crosstalk" and an increased incidence of immune-mediated diseases like asthma [11, 22, 31]. The strong effect of cesarean delivery of the development of childhood asthma has been observed both in our study and in further surveys [22, 31-33]. Thus, analyses of first-borns demonstrated that elective caesarean section was associated with an increased risk of dispensed inhaled corticosteroids in children aged between 2 and 5 years [32]. However, recent studies point out first, the presence of confounding factors, and second, they don't support the role of inadequate bacterial colonization during cesarean delivery and its association with childhood asthma [31, 32]. In this context, Nathan et al. reported that children delivered through caesarean sections did not have higher $\operatorname{IgE}$ levels nor were they more sensitized to aeroallergens, while multiple logistic regression show that asthma was significantly associated with a positive family history of atopy [33]. In turn, Kolokotroni et al. concluded from adjusting to potential confounders that association between cesarean delivery and asthma diagnosis in children indicates that family history of allergies may modify the effect of cesarean delivery on atopy [34]. Specifically, these authors observed a two-fold increase in the odds of being atopic among children with a familiar heredity if born by cesarean section, but any association was evidenced in children without a family history for allergic pathologies. Furthermore, Almqvist et al. observed that only emergent obstetrical intervention accounted for increased asthma diagnosis and medication during year of follow-up in children born with cesarean delivery, whereas elective section was insignificant [31]. Concluding that vaginal microflora plays no casual effect of the association with delivery mode and childhood asthma, these authors postulated that a more probable explanation should be sought in the indications for emergency cesarean section. Possibly, emergency cesarean delivery is a marker for cumulative maternal and prenatal stress, as long as these mothers are more likely to have asthma and higher stress is associated with increased IL-13 and decreased IFN-gamma [10]. If true, an additional adjusting for the stress would have suppressed the association between emergency cesarean delivery and the development of asthma [31]. Especially in developing countries, it is likely that expensive elective cesarean delivery is actually preferred by mothers with high socioeconomic status, whereas among mothers with low socioeconomic status emergency cesarean sections are generally applied to unexpected complications and constitutes a supplemental stressor. In fact, maternal cumulative adversity and lower maternal childhood socioeconomic status is also associated with increased cord blood $\mathrm{IgE}$ levels, asthma and repeated wheeze through both direct and indi- 
rect effects [35-37]. The association of elective cesarean delivery with childhood asthma observed in previous surveys may account for the confounding role of family atopy background, which in fact, should be associated with deviation from traditional life [15, 32, 34]. After adjustment for interfering confounding factors, the elective cesarean section seems to play no causative effect of the development of childhood asthma [31].

\section{Conclusion}

This study supports the idea that atopic dermatitis is better indicator of a potential asthma development during childhood as compared to family history for atopic disease; however, they seem to be only an evident externalization of what lies in the genes. Moreover, our data indicate that children with suburban origin, but in the same time metropolis residents of a developing country like Albania, are subjects of de novo exposure to a wide variety of risk factors of asthma development, such as cesarean delivery, high humidity inside the dwellings and passive tobacco smoke during the first life year. Consequently, the avoidance of these factors during this immunologically fragile period may prevent this scenario $[6,38]$. Nevertheless, the role of protective factors of breast feeding, respiratory infections in early life, and a "healthy" indoor environment needs further evaluation. Additional detailed studies are necessary for the detection of real asthma triggers, which could be hidden behind the well-determined risk factors.

\section{References}

[1]. Wong GW, Chow CM (2008) Childhood asthma epidemiology: insights from comparative studies of rural and urban populations. Pediatr Pulmonol 43(2): 107-116

[2]. Papadopoulos NG, Agache I, Bavbek S, Bilo BM, Braido F, et al. (2012) Research needs in allergy: an EAACI position paper, in collaboration with EFA. Clin Transl Allergy 2(1): 21.

[3]. Kim JH, Ellwood PE, Asher MI (2009) Diet and asthma: looking back, moving forward. Respir Res 10: 49.

[4]. Ballardini N, Kull I, Lind T, Hallner E, Almqvist C, et al. (2012) Development and comorbidity of eczema, asthma and rhinitis to age 12: data from the BAMSE birth cohort. Allergy 67(4): 537-544.

[5]. Dietert RR, Zelikoff JT (2008) Early-life environment, developmental immunotoxicology, and the risk of pediatric allergic disease including asthma. Birth Defects Res B Dev Reprod Toxicol 83(6): 547-560.

[6]. Wickman M, Melén E, Berglind N, Lennart Nordvall S, Almqvist C, et al. (2003) Strategies for preventing wheezing and asthma in small children. Allergy 58(8): 742-747

[7]. Patel MM, Quinn JW, Jung KH, Hoepner L, Diaz D, et al. (2011) Traffic density and stationary sources of air pollution associated with wheeze, asthma, and immunoglobulin E from birth to age 5 years among New York City children. Environ Res 111(8): 1222-1229.

[8]. Bakiri AH, Mingomataj EÇ, Ibranji A (2015) Role of antibiotics and infection-host interactions in the prevalence of respiratory atopy: experience and perspective. Open Allergy J 8: 1-6.

[9]. London SJ, Romieu I (2009) Gene by environment interaction in asthma. Annu Rev Public Health 30: 55-80.

[10]. Wright RJ, Visness CM, Calatroni A, Grayson MH, Gold DR, et al. (2010) Prenatal maternal stress and cord blood innate and adaptive cytokine responses in an inner-city cohort. Am J Respir Crit Care Med 182(1): 25-33.

[11]. Bracken MB, Belanger K, Cookson WO, Triche E, Christiani DC, et al. (2002) Genetic and perinatal risk factors for asthma onset and severity: a review and theoretical analysis. Epidemiol Rev 24(2): 176-189.

[12]. Su RC, Becker AB, Kozyrskyj AL, Hayglass KT (2008) Epigenetic regulation of established human Type 1 versus Type 2 cytokine responses. J Allergy Clin Immunol 121(1): 57-63.e3.

[13]. Grabenhenrich LB, Gough H, Reich A, Eckers N, Zepp F, et al. (2014) Early-life determinants of asthma from birth to age 20 years: A German birth cohort study. J Allergy Clin Immunol 133(4): 979-988.

[14]. Mingomataj EÇ, Xhixha F, Gjata E, Hyso E, Qirko E (2008) Prevalence of a family history of atopic disease among 3 generations of atopic respiratory patients in Tirana, Albania. J Investig Allergol Clin Immunol 18(3): 190-193.

[15]. Asher MI, Montefort S, Bjorksten B, Lai CK, Strachan DP, et al. (2006)
Worldwide time trends in the prevalence of symptoms of asthma, allergic rhinoconjunctivitis, and eczema in childhood: ISAAC Phases One and Three repeat multicountry cross-sectional surveys. Lancet 368(9537): 733-743.

[16]. Gilliland FD, Berhane K, Li YF, Rappaport EB, Peters JM (2003) Effects of early onset asthma and in utero exposure to maternal smoking on childhood lung function. Am J Respir Crit Care Med 167(6): 917-924.

[17]. Guerra S, Stern DA, Zhou M, Sherrill DL, Wright AL, et al. (2013) Combined effects of parental and active smoking on early lung function deficits: a prospective study from birth to age 26 years. Thorax 68(11): 1021-1028.

[18]. Gilliland FD, Berhane K, Islam T, Wenten M, Rappaport E, et al. (2003) Environmental tobacco smoke and absenteeism related to respiratory illness in schoolchildren. Am J Epidemiol 157(10): 861-869.

[19]. Hu Y, Liu W, Huang C, Zou ZJ, Zhao ZH, et al. (2014) Home dampness, childhood asthma, hay fever and airway symptoms in Shanghai, China: Associations, dose-response relationships and lifestyle's Influences. Indoor Air 24(5): 450-463.

[20]. Tischer CG, Hohmann C, Thiering E, Herbarth O, Müller A, et al. (2011) Meta-analysis of mould and dampness exposure on asthma and allergy in eight European birth cohorts: an ENRIECO initiative. Allergy 66(12): 1570-1579.

[21]. Nicolai T, Illi S, von Mutius E (1998) Effect of dampness at home in childhood on bronchial hyperreactivity in adolescence. Thorax 53(12): 10351040

[22]. Weng M, Walker WA (2013) The role of gut microbiota in programming the immune phenotype. J Dev Orig Health Dis 4(3): 203-214.

[23]. Björkstén B, Aït-Khaled N, Innes Asher M, Clayton TO, Robertson C, et al (2011) Global analysis of breast feeding and risk of symptoms of asthma, rhinoconjunctivitis and eczema in 6-7 year old children: ISAAC Phase Three. Allergol Immunopathol (Madr) 39(6): 318-325.

[24]. Brew BK, Kull I, Garden F, Almqvist C, Bergström A, et al. (2012) Breastfeeding, asthma, and allergy: a tale of two cities. Pediatr Allergy Immunol 23(1): 75-82.

[25]. Kull I, Almqvist C, Lilja G, Pershagen G, Wickman M (2004) Breast-feeding reduces the risk of asthma during the first 4 years of life. J Allergy Clin Immunol 114(4): 755-760.

[26]. Remes ST, Castro-Rodriguez JA, Holberg CJ, Martinez FD, Wright AL (2001) Dog exposure in infancy decreases the subsequent risk of frequent wheeze but not of atopy. J Allergy Clin Immunol 108(4): 509-515.

[27]. Lødrup Carlsen KC, Roll S, Carlsen KH, Mowinckel P, Wijga AH, et al. (2012) Does pet ownership in infancy lead to asthma or allergy at school age? Pooled analysis of individual participant data from 11 European birth cohorts. PLoS One 7(8): e43214.

[28]. Havstad S, Wegienka G, Zoratti EM, Lynch SV, Boushey HA, et al. (2011) Effect of prenatal indoor pet exposure on the trajectory of total IgE levels in early childhood. J Allergy Clin Immunol 128(4): 880-885.e4.

[29]. Lodge CJ, Lowe AJ, Gurrin LC, Matheson MC, Balloch A, et al. (2012) Pets at birth do not increase allergic disease in at-risk children. Clin Exp Allergy 42(9): 1377-1385.

[30]. Stoltz DJ, Jackson DJ, Evans MD, Gangnon RE, Tisler CJ, et al. (2013) Specific patterns of allergic sensitization in early childhood and asthma $\&$ rhinitis risk. Clin Exp Allergy 43(2): 233-241.

[31]. Almqvist C, Cnattingius S, Lichtenstein P, Lundholm C (2012) The impact of birth mode of delivery on childhood asthma and allergic diseases-a sibling study. Clin Exp Allergy 42(9): 1369-1376.

[32]. Bråbäck L, Ekéus C, Lowe AJ, Hjern A (2013) Confounding with familial determinants affects the association between mode of delivery and childhood asthma medication -- a national cohort study. Allergy Asthma Clin Immunol 9(1): 14 .

[33]. Nathan AM, de Bruyne J, Khalid F, Arumugam K (2012) Caesarean section and asthma in Malaysian children: a case-control study. Asian Pac J Allergy Immunol 30(3): 204-208.

[34]. Kolokotroni O, Middleton N, Gavatha M, Lamnisos D, Priftis KN, et al. (2012) Asthma and atopy in children born by caesarean section: effect modification by family history of allergies - a population based cross-sectional study. BMC Pediatr 12: 179 .

[35]. Sternthal MJ, Coull BA, Chiu YH, Cohen S, Wright RJ (2011) Associations among maternal childhood socioeconomic status, cord blood IgE levels, and repeated wheeze in urban children. J Allergy Clin Immunol 128(2): $337-$ 345.e1.

[36]. Peters JL, Cohen S, Staudenmayer J, Hosen J, Platts-Mills TA, et al. (2012) Prenatal negative life events increases cord blood IgE: interactions with dust mite allergen and maternal atopy. Allergy 67(4): 545-551.

[37]. Hack M, Youngstrom EA, Cartar L, Schluchter M, Taylor GH, et al. (2005) Predictors of internalizing symptoms among very low birth weight young women. J Dev Behav Pediatr 26(2): 93-104.

[38]. Peroni DG, Chatzimichail A, Boner AL (2002) Food allergy: what can be done to prevent progression to asthma? Ann Allergy Asthma Immunol 89(6 Suppl 1): 44-51. 